\title{
Rebranding Koperasi INTAKO Melalui Program Redecor Showroom dan Pemberdayaan Digital Marketing
}

\author{
${ }^{1}$ Fitria Widiyani Roosinda, ${ }^{2}$ Farah Aulia Salshabila \\ Program Studi Ilmu Komunikasi, FISIP, Universitas Bhayangkara Surabaya \\ Email: ${ }^{1}$ firia@ubhara.ac.id, ${ }^{2}$ farahbilla17@gmail.com
}

\section{Article Info}

Submitted: 21 April 2020

Revised: 11 June 2020

Accepted: 9 March 2021

Published: 21 April 2021

Keywords: rebranding,INTAKO, digital marketing, Instagram
Kata kunci: rebranding, INTAKO, digital marketing, Instagram

\section{Abstract}

Koperasi INTAKO (Bag and Luggage Industry) is a small industry that is also home to leather crafters in Tanggulangin. Since the occurrence of the Lapindo mudflow in 2006, this industry has gone out of business. Many crafters turn into factory workers. The condition of INTAKO is experiencing a crisis, due to the reduced number of craftsmen and the lack of buyers. Moreover, obstacles also come from increasingly intense market competition, especially in the bag industry. The obstacles from the wave of cheap imported goods became the main competitor for craftsmen in the southern region of Sidoarjo. Beginning in 2017, INTAKO began to develop again. The managers make a program that attracts the number of buyers and fixes internally. To support this effort, Bhayangkara University conducted a Thematic Community Service Program at INTAKO. The program is a rebranding in the form of redecorating the showroom, adding supporting components for product displays and empowering digital marketing through creating an Instagram account along with product photo content. The program aims to increase INTAKO branding by producing a showroom with iconic photo spots and increasing awareness and understanding of INTAKO management and employees about the importance of using social media as a platform for promotion and increasing product sales. There are 3 steps to be carried out, namely decorating the placement of superior products from crafters, optimizing digital marketing through taking product photos and creating an Instagram account. The results obtained, currently INTAKO already has a showroom specifically for new products and superior products and has a digital database of product photos. This digital promotional media will increase the number of sales of leather bag products and make people more familiar with the bag and luggage industry in Tanggulangin, Sidoarjo.

\section{Abstrak}

Koperasi INTAKO (Industri Tas dan Koper) merupakan industri kecil yang juga rumah bagi para perajin kulit di Tanggulangin. Sejak 
terjadinya lumpur Lapindo tahun 2006, industri ini sempat gulung tikar. Banyak perajin yang beralih menjadi buruh pabrik. Kondisi INTAKO mengalami krisis, dikarenakan berkurangnya jumlah perajin dan sedikitnya pembeli. Tak hanya itu, rintangan juga datang dari semakin ketatnya persaingan pasar, terutama pada industri tas. Rintangan dari gelombang barang impor yang murah menjadi pesaing utama bagi perajin di kawasan selatan Sidoarjo ini. Awal tahun 2017, INTAKO mulai berkembang kembali. Para pengurus membuat program yang menarik jumlah pembeli dan membenahi internal. Guna mendukung usaha ini, Universitas Bhayangkara melakukan KKN Tematik di INTAKO. Program yang dilakukan adalah melakukan rebranding berupa mendekor ulang showroom tas, penambahan komponen pendukung untuk display produk serta memberdayakan digital marketing melalui pembuatan akun Instagram beserta konten foto produk. Program ini bertujuan agar meningkatkat branding INTAKO dengan menghasilkan showroom disertai spot foto yang iconic dan meningkatkan kesadaran dan pemahaman kepada pengurus serta karyawan INTAKO tentang pentingnya penggunaan sosial media sebagai platform untuk promosi dan meningkatkan penjualan produk. Ada 3 tahap yang dilakukan, yaitu mendekorasi penempatan produk unggulan dari perajin, mengoptimalkan digital marketing melalui pengambilan foto produk, dan pembuatan akun Instagram. Hasil yang didapat, saat ini INTAKO sudah memiliki showroom khusus produk baru dan produk unggulan dan memiliki database digital mengenai foto-foto produk. Media promosi digital ini akan menambah peningkatan jumlah penjualan produk tas kulit dan membuat masyarakat lebih mengenal industri tas dan koper di Tanggulangin, Sidoarjo ini.

\section{PENDAHULUAN}

Komponen terbesar masyarakat Desa Kedensari, Kecamatan Tanggulangin adalah pengrajin kulit. Akibat dari terjadinya luapan lumpur Lapindo, hampir 70 persen perajin di Tanggulangin mengalami gulung tikar, mereka yang masih bertahan hanya beroperasi berdasarkan pesanan saja (Hadi Noviono dan Dyah Pelitawati, 2019). Seiring berjalannya waktu, para perajin mulai bangkit dan memulai bisnisnya kembali. Namun, banyak kendala yang dihadapi. Banyak diantara perajin kulit Tanggulangin yang belum memiliki outlet sendiri sehingga bekerjasama dengan INTAKO selaku koperasi yang menerapkan sistem konsinyasi. Koperasi INTAKO merupakan tempat berbelanja untuk masyarakat yang menyukai kerajinan kulit, namun design interior dan letak display belum dioptimalkan. Penampilan desain interior sangatlah penting.
Desain interior mempengaruhi konsumen dalam mengambil keputusan pembelian karena mempermudah dan membuat konsumen merasa betah (Muwaffaq, Hadi. 2018). Desain toko yang dapatmemberikan rasa nyamakepadapelanggan, akan membuat pelanggan menjadi betah dan cenderung membuat mereka menggunakan waktunya untuk berkeliling menikmati suasana toko (Suhartanto et al, 2017:192) Selain itu, display produk juga sangat menunjang. Vita Dhameria (2014) mengungkapkan, display produk harus diatur sebaik mungkin agar konsumen mudah memperoleh produk dan juga penyusunan barang-barang yang memudahkan konsumen melihat, mencari, dan menjangkau hal ini akan mempengaruhi pembelian impulsif yang dilakukan seorang konsumen. Sedangkan (Wardhana \& Rochmaniah, 2008) mengatakan, Display product (penataan barang) berperan sangat penting agar konsumen yang tadinya 
hanya sebatas melihat produk menjadi tertarik untuk membeli.

Selain bidang interior dan display produk, bidang digital marketing-nya sama sekali tidak dioptimalkan untuk kegiatan promosi maupun penjualan. Revolusi teknologi informasi telah mengubah lanskap dunia pemasaran dalam beberapa tahun terakhir ini. Metode komunikasi pemasaran yang sebelumnya bersifat tradisional dan konvensional, kini telah terintegrasi dalam dunia digital (Ascharisa Mettasatya Afrilia, 2018). Media sosial mendorong kemudahan pemasaran produk dan jasa melalui komunikasi online yang dilakukan melalui gadget. Promosi yang berbentuk konten membuka kesempatan komunikasi dengan calon konsumen bahkan hingga terjadi transaksi (R Hartono, 2020).

Mengingat hal tersebut, sudah banyak pelaku bisnis baik kecil maupun besar yang beralih ke pemasaran secara digital, sehubungan terhadap ketatnya persaingan dengan kompetior. Dengan diimbangi strategi pemasaran serta media yang tepat, kegiatan penjualan akan berjalan dengan lancar, pesanan meningkat dan profit. Kami melihat potensi bahwa tempat ini bisa menjadi wisata yang menarik untuk spot foto dan dengan adanya koper besar INTAKO sebagai icon-nya serta dengan mengoptimalkan akun media sosial dan membuat foto produk yang bagus untuk promosi dan penjualan. Berdasarkan hal tersebut, kelompok kami menggiatkan program digital marketing. Definisi digital marketing sebagai penggunaan teknologi untuk membantu aktivitas pemasaran yang bertujuan untuk meningkatkan pengetahuan konsumen dengan cara menyesuaikan dengan kebutuhan mereka. Program tersebut sangat sesuai jika dihadapkan pada kondisi masyarakat saat ini (Chaffey, 2013).

Masyarakat Indonesia kian hari kian terkoneksi dengan internet. Data dari Asosiasi Penyelenggara Jasa Internet Indonesia, dari lebih 262 juta orang penduduk, 143,26 juta jiwa telah mengakses internet (APJII, 2018). Pada program digital marketing ini, media yang dipilih adalah Instagram sebagai platform, Instagram kini media yang sudah mendunia. Adapun pengguna Instagram diperkirakan mencapai 400 juta pengguna di seluruh dunia sejak kemunculannya pada tahun 2010 hingga awal 2015 (Paul, 2015). Instagram saat ini sedang populer di Indonesia. Data yang dilansir oleh Katadata.co.id menyebutkan bahwa jumlah pengguna Instagram Indonesia telah mencapai 55 juta pengguna (2018).

Dari data-data tersebut menunjukkan peluang yang besar untuk memanfaatkan Instagram sebagai media promosi INTAKO. Pelaku bisnis online mengaku lebih mudah memasarkan produknya melalui Instagram karena sasaran pertama adalah orang yang paling dekat dengannya, bisa juga melalui teman yang awalnya dari mulut ke mulut sambil menunjukan akun Instagram, komunikasi tersebut sangat efektif bagi para penjual, dengan adanya media Instagram semakin mudahnya penjual menunjukkan foto atau katalaog barang jualannya (Wibowo, Haryokusumo, 2020). Dengan demikian usaha rumahan juga kecilkecilan bisa menggunakan media sosial untuk menawarkan produk masing-masing dan memanfaatkan media sosial Instagram sebagai alat mencari keuntungan (Fadli, 2017).

Adapun manfaat dan tujuan dari kegiatan tersebut adalah agar dapat mengoptimalkan showroom sekaligus spot foto serta pembuatan instagram serta sesi foto produk agar dapat menunjang rebranding INTAKO. Langkah tersebut juga disertai dengan koordinasi dengan karyawan agar dapat melanjutkan kegiatan promosi dan penjualan melalui instagram.Dalam menunjang program tersebut, ada beberapa aspek yang sudah kami analisa diantaranya:

\section{Bidang Geografis}

Koperasi INTAKO terletak di Kecamatan Tanggulangin, Kabupaten Sidoarjo. Secara geografis, Sidoarjo terletak di daerah dataran rendah dan berada di antara dua aliran sungai besar, yaitu Kali Mas dan Kali Porong, keduanya adalah pecahan dari kali Brantas. Oleh karena itu, Sidoarjo dikenal dengan sebutan Kota Delta (M. Hafidz Wahyu A \& Eko Agus Basuki Oemar, 2016). Sedangkan kondisi geografis Kecamatan Tanggulangin berbatasan langsung dengan 3 Kecamatan yaitu Kecamatan Candi di sebelah utara, Kecamatan Candi dan Kecamatan Porong di sebelah timur, Kecamatan Porong di sebelah selatan dan Kecamatan Tulangan di sebelah barat. Kecamatan Tanggulangin merupakan salah 
satu kecamatan yang terletak \pm 6 meter dari permukaan laut dan antara 7,48o-7,52o lintang selatan dan $112,67 \mathrm{o}-112,75 \mathrm{o}$ bujur timur dengan jarak kurang lebih $6 \mathrm{~km}$ dari ibu kota Kabupaten Sidoarjo (Hadi Noviono dan Dyah Pelitawati, 2019).

2. Bidang Sosial dan Budaya

Kerukunan dan kebersamaan bisa dikatakan sebagai modal sosial terbesar yang dimiliki oleh koperasi INTAKO. Masyarakat menjunjung tinggi nilainilai tersebut. Masyarakat di koperasi INTAKO juga tergolong masyarakat yang melestarikan budaya kesenian tradisional. Seperti pengembangan kesenian dalam industri kulit menjadi tas yang masih memberikan nuansa batik dan songket. Regenerasi kesenian ini juga berlangsung baik, para anak-anak di kawasan sekitar sangat antusias belajar kesenian merajin seperti ini.

3. Bidang Ekonomi

Koperasi INTAKO adalah tempat yang sangat kaya akan potensi sumber dayanya. Banyak masyarakat yang belum mempunyai kesadaran untuk memanfaatkan potensi yang ada. Dari masa ke masa, koperasi INTAKO beberapa kali menghadapi permasalahan. Setelah krisis ekonomi, menurut informasi yang kami dapat, kurangnya keinginan untuk mencapai lebih yang dimiliki oleh karyawan maupun masyarakat sekitar membuat koperasi INTAKO yang dulu berjaya dan kini perlahan redup karena isu lumpur Lapindo yang membuat konsumen koperasi INTAKO menurun. Tak hanya itu, serbuan produk dari luar negeri yang memiliki harga kompetitif namun kwalitasnya kurang baik juga menjadi halangan tersendiri bagi perajin dan koperasi INTAKO. Karena sebagian besar masyarakat yang menetap di Tanggulangin hanya mengandalkan hasil usaha merajin kulit. Belum selesai disitu, beberapa kendala yang ditemui dalam bidang ekonomi yang lain terletak pada kurang optimalnya masyarakat untuk mengeksplorasi sumber daya manusianya. Padahal jika dikembangkan mereka bisa mendapatkan laba dua kali lipat dibanding menjualanya secara apa adanya.

4. Bidang Teknologi

Permasalahan pokok yang di peroleh dari bidang teknologi tentang keadaan dari karyawan di koperasi INTAKO adalah salah satunya lingkungan sekitar yang kurang mendukung. Kebanyakan para karyawan di sini kurang memiliki pengetahuan tentang pemanfaatan teknologi modern pada era masa kini. Kurangnya pemahaman tentang seberapa besar pengaruh dunia digital apabila bisa dioptimalkan dengan baik juga menjadi permasalahan di bidang teknologi ini. Padahal jika mereka mampu menguasai perkembangan teknologi sekarang, koperasi INTAKO pasti dapat meraup keuntungan yang lebih besar, mengingat media sosial dan e-commerce sekarang sedang naik daun dalam membantu promosi maupun penjualan para produsen.

\section{Bidang Pariwisata}

Dalam bidang pariwisata koperasi INTAKO merupakan ikon dari Kecamatan Tanggulanin dan sering menjadi tujuan berkunjung para wisatawan untuk membeli hasil karya masyarakat sekitar ataupun hanya untuk sekedar berkeliling saja. Biasanya yang sering berkunjung adalah ibu-ibu terutama yang suka berbelanja tas ataupun dompet. Para perajin lokal telah membuktikan bahwa mereka masih mampu membuat berbagai macam kerajinan kulit yang bisa langsung dijual, walaupun sempat menurun karena kejadian lumpur Lapindo yang memaksa untuk gulung tikar serta derasnya arus masuk barang import terutama tas dengan harga yang murah.

\section{METODE}

Kegiatan pengabdian ini diawali dengan tahap pengumpulan informasi berupa berupa keadaan kondisi lokasi dan kebutuhan dari pihak INTAKO. Tahap berikutnya adalah brainstorming. Brainstorming adalah suatu bentuk diskusi dalam rangka menghimpun gagasan, pendapat, informasi, pengetahuan, pengalaman, dari semua peserta. Berbeda dengan diskusi, di mana gagasan dari seseorang dapat ditanggapi (didukung, dilengkapi, dikurangi, atau tidak 
disepakati) oleh peserta lain, pada penggunaan metode brainstorming pendapat orang lain tidak untuk ditanggapi (Sutikno, 2007). Brainstorming pertama kali dilakukan bersama seluruh Tim KKN terkait konsep dan tahapantahapan implementasi berikutnya. Kemudian brainstorming dilanjutkan dengan melibatkan Ketua serta Pengurus INTAKO dengan tujuan memberikan gambaran konsep program kedepannya.

Selanjutnya implementasi program redecor interior. Redecor interior meliputi memperbaiki bagian depan yaitu penataan ulang display layout produk, perbaikan komponen-komponen pendukung koperasi serta menciptakan spot foto iconic INTAKO. Tata ruang toko yang bagus membantu pelanggan mencari dan membeli barang (Utami, 2012:282). Suasana lingkungan toko menjadi salah satu alasan yang mempunyai dampak besar terhadap niat beli ulang dan emosi yang dibangun (Hussain, 2016). Menurut Sangadji \& sopiah (2016:318) menjelaskan bahwa tidak boleh asal-asalan atau sembarangan karena store layout yang baik akan membantu retailer agar bisa menampilkan produknya dengan baik dan memudahkan konsumen ketika berbelanja. Apabila toko sudah tertata dengan baik, rapi diharapkan ruangan toko menjadi nyaman, menyenangkan, dan enak di pandang, sehingga pengunjung akan merasa enak saat berbelanja.
Penataan ulang layout produk bertujuan untuk memperbarui letak posisi produk agar lebih rapi dan mengikuti trend. Store layout adalah tata letak produk, kasir, dan arus lalu lalang konsumen dalam toko. Pengelola toko harus mempunyai rencana dalam penentuan lokasi dan fasilitas toko dan memanfaatkan ruangan toko yang ada seefektif mungkin (Isnawati, 2020). Pengubahan layout produk ini dilakukan dengan memilih produk-produk terbaru untuk diletakkan di posisi utama agar lebih mudah dilihat oleh calon pembeli yang mengunjungi showroom mengingat posisi layout produk sebelumnya kurang maksimal. Tata letak didefinisikan sebagai pembagian daerah penjualan, pemanfaatan ruang serta penataan produk (Banat dan 22 Wandebori, 2012) Pengecatan ulang pada tembok showroom juga dilakukan agar menciptakan suasanayang senada dengan konsep redecor, yaitu monochrome. Salah satu faktor yang dapat mempengaruhi perilaku konsumen ketika berbelanja adalah melalui pemilihan warna pada suatu toko (Banat dan Wandebori, 2012). Menurut Aini (2016) suasana toko dapat merangsang emosi konsumen ketika memutuskan suatu pembelian di mana rangsangan tersebut tercipta melalui desain lingkungan visual, cahaya, musik, aroma, maupun warna dari toko.

Perbaikan komponen pendukung showroom juga dilakukan seperti mengganti display produk

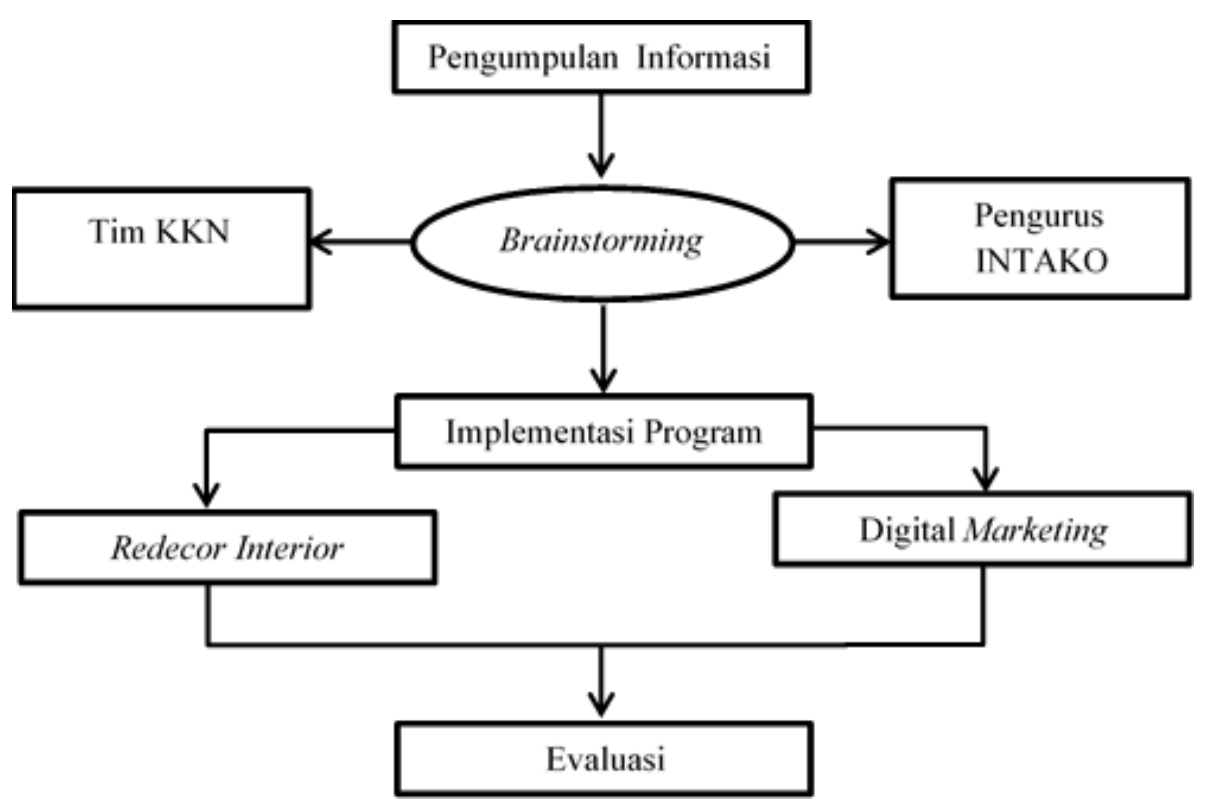

Gambar 1. Metode Pelaksanaan 
dengan membuatkan rak yang lebih minimalis dan kekinian dengan tujuan supaya tidak merusak produk mengingat sebelumnya produk didisplay menggunakan paku gantung yang akan merusak bahan dari tas. Selain itu, dilakukan juga pembenahan layout. Layout merupakan usaha untuk menyusun, menata, atau memadukan elemen-elemen atau unsur-unsur komunikasi grafis (teks, gambar, tabel, dll) menjadikan komunikasi visual yang komunikatif, estetik, dan menarik (Rifianita, R. Sugeng Basoeki, 2019). Penataan dimulai dari mengubah rak yang semula terlihat kaku dan monoton ditambahkan dengan aksen hiasan tanaman sintetis agar bervariasi dan terlihat lebih segar. Proses ini dilakukan agar menciptakan showroom yang terlihat baru dan segar. Berman dan Evans (dalam Pramatatya, 2015) mengemukakan mengenai teori interior bahwa general interior yang menarik dapat mencuri perhatian pengunjung dan dapat memudahkan mereka dalam proses pengambilan keputusan pembelian.

Untuk mengisi ruang yang kosong dan tidak terpakai, dibuat satu tembok baru untuk diisi lebih banyak produk lagi supaya produk tidak menumpuk pada satu tempat saja. Desain toko yang baik akan menarik banyak pelanggan untuk datang, karena desain toko merupakan strategi penting untuk menciptakan suasana yang mampu membuat konsumen merasa ingin berlama-lama dalam suatu toko (Suhartanto dkk., 2017). Pada bagian dinding dipasang hiasan dinding berupa quotes-quotes yang terbuat dari lukisan kayu dengan warna-warni senada. Penambahan hiasan dinding juga bertujuan untuk menambah spot foto pengunjung. Tidak hanya itu, juga ditambahkan cermin di tengahtengah rak display produk yang bertujuan agar calon pembeli dapat melihat dan mencoba tas yang akan dibeli. Desain toko (store design) merupakan strategi penting untuk menciptakan suasana yang akan membuat pelanggan merasa betah berada dalam suatu toko atau gerai (Ma'ruf, 2005:204). Konsumen yang berada di dalam gerai dalam waktu yang lama akan dapat meningkatkan potensi pembelian tidak terencana yang dilakukannya (Setiawati dan Sukawati, 2017).

Setelah itu, tahap pengoptimalan digital marketing. Digital marketing yang biasanya terdiri dari pemasaran interaktif dan terpadu memudahkan interaksi antara produsen, perantara pasar, dan calon konsumen. Di satu sisi, digital marketing memudahkan pebisnis memantau dan menyediakan segala kebutuhan dan keinginan calon konsumen, di sisi lain calon konsumen juga bisa mencari dan mendapatkan informasi produk hanya dengan cara menjelajah dunia maya sehingga mempermudah proses pencariannya (Purwana ES, Dedi, Rahmi, Aditya, 2017). Bagi sebagian besar netizen Indonesia, penggunaan media sosial sudah menjadi keseharian rutin. Layanan seperti Youtube, Facebook, WhatsAp, dan Instagram adalah empat layanan internet yang paling diminati oleh orang Indonesia (We Are Social, 2018). Berlatar belakang dengan semakin ketatnya persaingan produk fashion khususnya tas, produk INTAKO tidak hanya dipasarkan melalui showroom secara offline saja namun juga dilakukan secara online yaitu pemasaran melalui media sosial.

Menurut Van Dijk (dalam Novita Sari, 2018) media sosial adalah platform media yang memfokuskan pada eksistensi pengguna yang memfasilitasi mereka dalam beraktivitas maupun berkolaborasi. Media sosial juga bisa dijadikan sebagai sarana interaksi dengan konsumen (Mershon, 2011). Media sosial merupakan alat promosi bisnis yang efektif karena dapat diakses oleh siapa saja, sehingga jaringan promosi bisa lebih luas (Bate'e, 2019). Media Instagram dipilih sebagai media untuk memasarkan produk INTAKO secara online. Instagram adalah aplikasi gratis untuk berbagi foto yang memungkinkan penggunanya untuk mengambil foto dan selanjutnya berbagi pada layanan jejaring sosial (Zadmehr et al., 2016).

Menurut Muttaqin (2011) dalam Kurniawan (2017) mengatakan Instagram marketing adalah melakukan aktivitas marketing menggunakan semua fasilitas yang disediakan oleh instagram dengan tujuan meningkatkan penjualan (sales) dan menjalin komunikasi lebih langgeng dengan pelanggan (customer relationship). Dari pertimbangan tersebut maka dibuatlah akun Instagram bisnis bagi INTAKO dengan nama @ intako.tanggulangin. Melalui fitur berbagigambar instagram unggul dalam menyita perhatian dari masyarakat Indonesia, para pengguna internet di Indonesia sangatlah senang menggunakan 
instagram sebagai salah satu aktivitas seru yang dilakukan, secara otomatis para pelaku bisnis melihat peluang yang ada di media online tersebut (Sofia, 2017). Konsumen dimudahkan dengan adanya instagram bisa melihat produk yang ditawarkan bahkan juga bisa memberikan pertanyaan dikolom komentar pada gambar produk yang diminati (Fadli, 2017).

Para pelaku bisnis dan usaha melihat peluang besar yang ada di media online instagram tersebut untuk digunakan jualan online nya mulai dari tas, sepatu, baju fashion, hingga kuliner (Fadli, 2017). Memanfaatkan Instagram bertujuan untuk media komunikasi pemasaran adalah memberikan suatu kekuatan kepada khalayak agar tidak mudah menyerah dan selalu bertahan di dunia bisnis (Yudhi, 2018). Untuk memaksimalkan proses pemasaran, dilaksanakan beberapa strategi pemasaran yaitu pengambilan foto produk yang professional, pembuatan konten instagram serta kegiatan promosi produk. Promosi merupakan perangkat penting dalam pemasaran global yang harus dirancang untuk membantu perkembangan perbuatan baik dan memberi informasi yang akurat dan tepat waktu, khususnya dalam situasi krisis (M. Hafidz Wahyu A \& Eko Agus Basuki Oemar, 2016).

Pengambilan foto produk diberi konsep casual karena sangat sesuai dengan koleksi unggulan yang didisplay di showroom. Banyak orang yang memanfaatkan instagram sebagai sarana untuk berbisnis dengan cara mengunggah foto produk yang akan mereka pasarkan dengan berbagai variasi efek gambar yang dapat menarik pembeli (Dewi Kurniawati \& Nugraha Arifin, 2015). Selain sebagai sosial media, aplikasi Instagram juga menjadi wadah dan aktivitas promosi penjualan yang mudah dan efektif, Instagram juga memiliki banyak keuntungan untuk pelaku pasar, seperti contohnya adalah penjual atau pelaku pasar tidak usah menggunakan biaya agar bisa menawarkan produk mereka, dengan begitu pelaku pasar bisa sepuasnya untuk berpromosi agar pasar bisa dikuasai oleh produk tersebut.

Selain itu Instagram juga mengalami pembaharuan yang bisa diunggulkan dari media yang lain, pembaharuannya adalah Instagram bisa diatur oleh pengguna untuk melakukan penjualan atau promosi produk di instagram 3 tersebut. Dengan begitu sesudah disetting maka Instagram dengan otomatis produk akan memasarkan dengan sendirinya setelah mensetting dipengaturan Instagram tadi (Puguh, 2017). Hasil dari proses photoshoot ini kemudian Tim KKN olah menjadi postingan dengan konsep senada untuk feed Instagram koperasi INTAKO, sehingga customer bisa melihat sendiri kwalitas barang serta spesifikasi dari keterangan di foto tersebut. Hal ini bertujuan untuk memaksimalkan kegiatan pemasaran produk dan mengikuti perkembangan strategi bisnis yang sedang dilakukan oleh banyak pelaku bisnis di Indonesia.

\section{HASIL DAN PEMBAHASAN}

Pelaksanaan program KKN yang terangkum berlangsung dari tanggal 19 Januari 2020 hingga 23 Februari 2020 di Tanggulangin. Mengacu pada tahapan sesuai metode pelaksanaan, kegiatan pertama yang dilakukan adalah brainstorming, baik dilakukan bersama internal Tim KKN dan juga pihak INTAKO. Tahapan ini dilakukan berulang kali antara pihak INTAKO dengan para mahasiswa KKN dan dosen pembimbing. Hasil yang didapat dari proses brainstorming berupa informasi tentang kebutuhan serta permasalahan yang ada di INTAKO, yaitu kurangnya tenaga atau staf yang kompeten untuk mengoptimalkan pemasaran melalui media sosial. Staf di INTAKO hampir sebagian besar belum menguasai pemasaran digital sebab selama ini hanya mengandalkan pemasaran secara konvensional saja. Pendidikan para staf yang rata-rata lulusan SMP dan faktor usia juga berpengaruh terhadap pengetahuan di bidang pemasaran digital tersebut.

Untuk mengatasi permasalahan ini, tim melatih para staf INTAKO terutama staf yang berusia muda untuk menggunakan metode pemasaran secara digital. Pelatihan yang diberikan selama seminggu dua kali selama sebulan dengan durasi dua jam. Tenaga pelatih adalah para dosen yang kompeten dibidang pemasaran digital. Materi pelatihan disesuaikan dengan tahapan pemasaran digital yang akan dilatihkan kepada para staf. Pada proses ini, tim pelatih juga melakukan tes dan evaluasi terhadap para staf guna mengukur seberapa 
besar pemahaman mereka dalam menggunakan pemasaran secara digital.

Mengenai pembahasan secara intens tentang konsep redecor yang sesuai dengan kesepakatan bersama antara Tim KKN dan Pengurus INTAKO, hal ini juga diselesaikan dengan cara membuat ruangan showroom yang dikhususkan bagi produk-produk tas dengan kualitas bahan yang terbaik. Selama ini INTAKO tidak memiliki ruang pamer yang digunakan untuk memajang produk dalam kategori produk unggulan. Pembuatan redecor ini penting dilakukan dengan tujuan agar pengunjung dapat dengan mudah membedakan mana produk unggulan dan mana produk yang non unggulan. Kualitas produk unggulan menggunakan bahan kulit yang baik dengan desain produk yang mengikuti trend fashion. Proses redecor menghasilkan tampilan ruangan yang terkesan mewah dengan interior yang menarik, diharapkan akan dapat menarik perhatian pengunjung INTAKO. Proses redecor dengan menata layout showroom tujuannya adalah agar lebih menarik pengunjung dengan penataan produk-produk unggulan serta pengoptimalan ikon INTAKO berupa tas koper besar yang digunakan sebagai spot foto (Gambar 2). Proses redecor dilanjutkan dengan pengecatan ulang dan membangun 1 tembok baru yang berfungsi sebagai tempat display produk dengan memberikan beberapa rak dan kaca yang dapat digunakan customer untuk mencoba produk dan berfoto (Gambar 3).

Hal yang lain adalah menjelaskan konsep dan alur program digital marketing yang akan dilaksanakan guna mengoptimalisasi pemasaran. Pihak INTAKO menginginkan penjualan produk bisa menghasilkan hasil yang signifikan dengan adanya pola digital marketing. Konsepnya pengunjung bisa membeli produk tanpa harus ke showroom, cukup hanya dengan melihat dan membeli produk dari media digital saja. Dengan adanya digital marketing maka pemasaran baik offline maupun online bisa sama-sama dilakukan sehingga akan menghasilkan capaian penjualan yang baik bagi INTAKO dan mewujudkan kesejahteraan bagi para pengrajin tas dan sepatu yang menjadi mitra INTAKO.

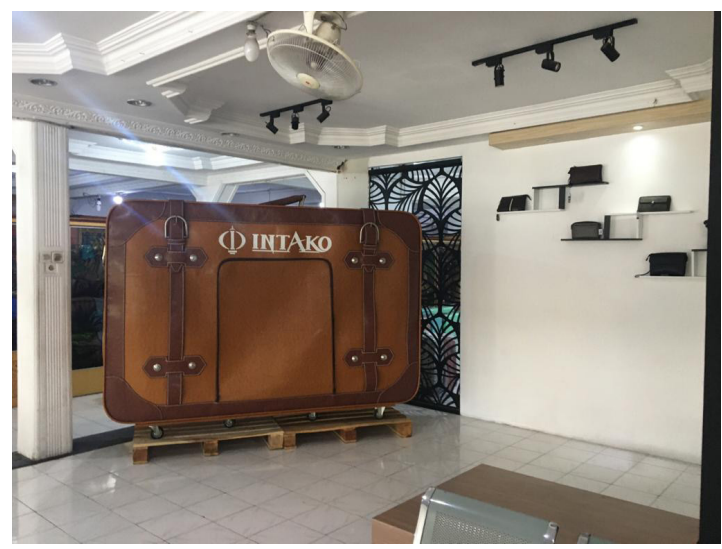

Gambar 2. Penataan Layout Showroom

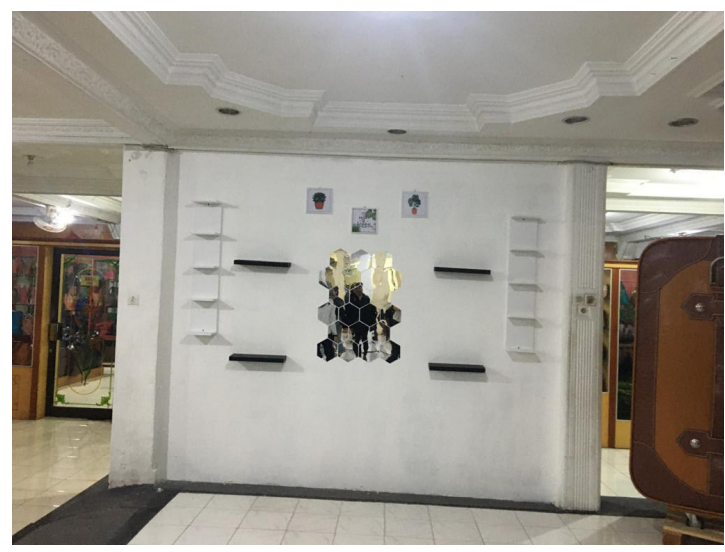

Gambar 3. Tembok Baru pada Showroom

Kegiatan selanjutnya adalah digital marketing. Kegiatan ini menghasilkan pemahaman tentang pentingnya pengoptimalan pemasaran melalui media digital kepada pengurus dan karyawan. Selain itu, dalam tahap ini Tim KKN membuat akun Instagram business untuk INTAKO yang dapat digunakan untuk keperluan pemasaran dan penjualan. Hasil dari program digital marketing yang lain diantaranya adalah beberapa koleksi foto produk hasil dari kegiatan photoshoot dengan menggunakan berbagai produk unggulan pilihan INTAKO (Gambar 4). Foto-foto tersebut diolah oleh Tim KKN menjadi foto dengan layout senada untuk feed instagram yang digunakan sebagai katalog online bagi koperasi INTAKO. Dari kegiatan tersebut, pihak koperasi INTAKO dapat memiliki pemahaman tentang teknik foto produk yang benar dan Instagram-able serta dapat menarik banyak customer melalui media online. Akun Instagram tersebut kemudian dis erah terimakan kepada ketua INTAKO di akhir upacara penutupan kegiatan KKN (Gambar 6). 


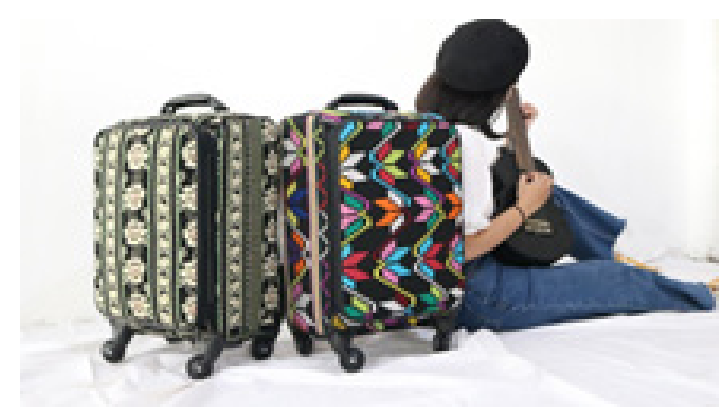

Gambar 4. Hasil Foto Produk

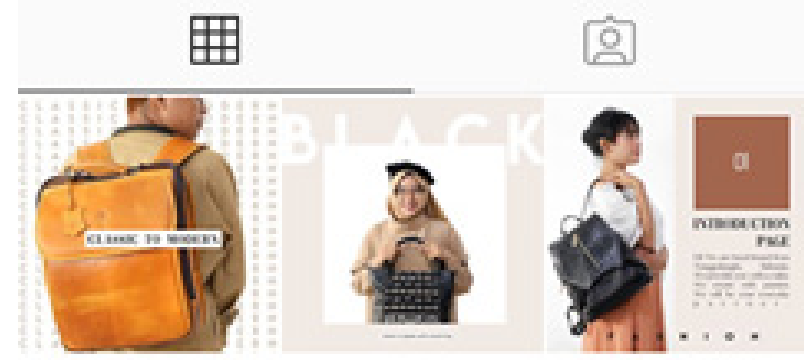

Gambar 5. Feed Instagram INTAKO

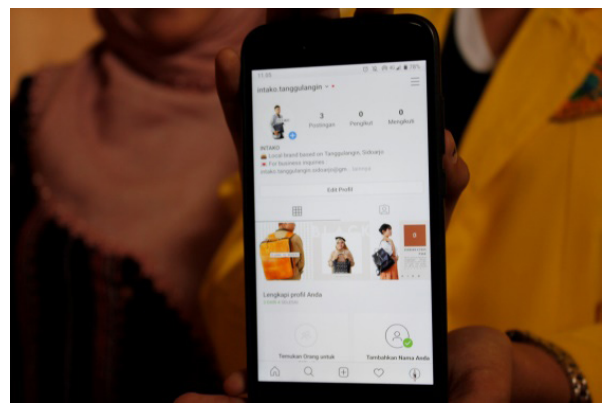

Gambar 6. Serah Terima Akun Instragram untuk INTAKO
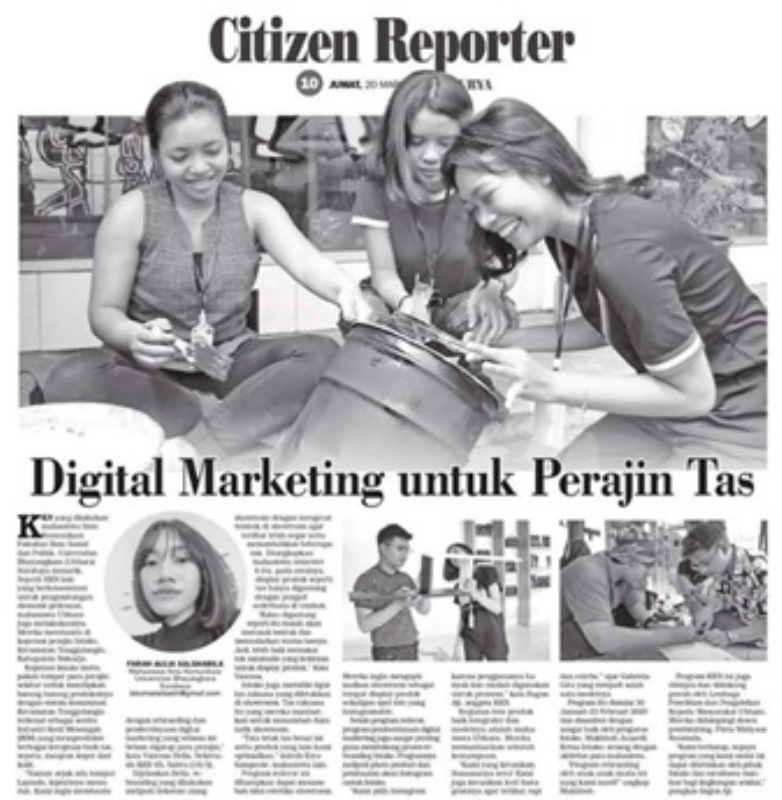

Pada tahap evaluasi, diketahui pengurus dan staf INTAKO merasa senang dan terbantu atas kegiatan-kegiatan yang dilaksanakan oleh tim KKN Ubhara. Diwakilkan oleh Ketua INTAKO Bapak Makhbub Junaedi, beliau mengungkapkan rasa terima kasihnya atas kerja sama yang telah dilakukan. Harapan beliau dan kami, semoga aset dan ilmu yang telah tercipta dapat terawat dan terus dimanfaatkan guna memajukan INTAKO dan mitra perajin sekitar.

\section{SIMPULAN}

Kegiatan redecor interior dan digital marketing sangat diperlukan untuk proses rebranding koperasi INTAKO. Edukasi kepada karyawan serta pengurus tentang pentingnya memperhatikan penataan layout produk, pengoptimalan setiap sudut agar dapat digunakan menjadi spot foto serta pentingnya pemberdayaan digital marketing guna menunjang pemasaran dan penjualan sangat memenuhi harapan INTAKO kedepannya. Untuk pihak INTAKO, semoga kedepannya dapat memperbaiki koordinasi antar pengurus agar dapat menciptakan iklim kerja yang positif dan kondusif terlebih bagi para customer serta stakeholder yang berkepentingan di INTAKO. Untuk pihak Universitas khususnya LPPM, untuk kedepannya supaya lebih meningkatkan koordinasi dan perbaikan dalam internal, agar pelaksanaan KKN pada tahun berikutnya dapat lebih baik.

\section{PERSANTUNAN}

Ucapan terima kasih ini kami sampaikan kepada Lembaga Penelitian dan Pengabdian Kepada Masyarakat serta perwakilan dari rektorat Universitas Bhayangkara Surabaya yang telah mendukung kegiatan Kuliah Kerja Nyata ini, Ketua INTAKO Bapak Makhbub Junaedi beserta seluruh karyawan dan warga Desa Kedensari, Tanggulangin, Sidoarjo, dan Camat Tanggulangin Bapak Sabino. Terima kasih juga kepada Harian Surya yang sudah meliput dan mendokumentasi kegiatan KKN. 


\section{REFERENSI}

Aini, Q. N. (2016). Pengaruh Atmosfer Toko dan Promosi Penjualan terhadap Shopping dan Pembelian Tidak Terencana (Survei terhadap Konsumen Giant Hypermarket Mall Olympic Garden). Jurnal Administrasi Bisnis (JAB)|, 37(1), 164-170.

Ascharisa Mettasatya Afrilia1. (2018). Digital Marketing sebagai Strategi Komunikasi. Jurkom, Riset Komunikasi, 1(1), 147-157.

Asosiasi Penyelenggara Jasa Internet Indonesia. 2018. Internet Penetration and Behaviour Survey 2018. APJII.

Bate'e MM. 2019. Pengaruh Media Sosial terhadap Keputusan Pembelian di Toko Kaosnias Gunungsitoli. Jurnal Ekonomi \& Ekonomi Syariah Vol 2 No 2.

Banat, A., \& Wandebori, H. S. T. (2012). Store Design and Store Atmosphere Effect on Customer Sales per Visit Economics, Management and Behavioral Sciences.

Banjaransari, Yudhi Gumbiro. 2018. Pemanfaatan Instagram sebagai Media Komunikasi Pemasaran Online Page Down Cloth Maker. Naskah Publikasi. Surakarta. Universitas Muhammadiyah Surakarta.

Chaffey, Dave \& Smith, PR. 2013. E-Marketing: Exellence. UK: Butterworth-Heinemann.

Dewi Kurniawati dan Nugraha Arifin, Strategi Pemasaran melalui Media Sosial dan Minat Beli Mahasiswa, Jurnal Simbolika Vol. 1 No. 2, September 2015, hlm. 194.

Hadi Noviono dan Dyah Pelitawati. 2019. Pengaruh Modal Kerja, Pendidikan dan Teknologi terhadap Pendapatan Usaha Mikro Kecil dan Menengah (UMKM) di Sentra Industri Tas dan Koper Tanggulangin. Jurnal Dinamika Administrasi Bisnis Vol. 5 No 2.

Hussain, R., dan Ali, M. (2015). Effect of Store Atmosphere on Customer Purchase Intention. International Journal of Marketing Studies. Vol. 7, No. 2, 35-42.

Isnawati. 2020. Pengaruh Atmosfer Toko terhadap Tanggapan Emosional dan Niat Pembelian Ulang di Luwes Gading Surakarta.

Kata Data. 2018. Berapa Pengguna Instagram dari Indonesia? Kata Data. Pranala: https://databoks. katadata.co.id/datapublish/2018/02/09/berapa-pengguna-instagramdari-indonesia.

Kurniawan, Puguh. 2017. Pemanfaatan Media Sosial Instagram sebagai Komunikasi Pemasaran Modern pada Batik Burneh. Jurnal Kompetensi, Vol 11, No 2, Oktober 2017.

Ma'ruf, Hendri. 2005. Pemasaran Ritel. Jakarta. PT Gramedia Pustaka Utama

Mershon, P. 2011. Small Businesses Moving Toward Social Media. Retrieved March 2012, 7 From Social Media Examiner.

Miranda, Sofia. 2017. Pengaruh Instagram sebagai Media Online Shopping Fashion terhadap Perilaku Konsumtif Mahasiswi Fakultas Ilmu Sosial dan Ilmu Politik Universitas Riau. Jurnal JOM FISIP Vol. 4 No.1 -Februari 2017.

M. Hafidz Wahyu A \& Eko Agus Basuki Oemar. 2016. Perancangan Desain Grafis Promosi Intako Sidoarjo. Jurnal Pendidikan Seni Rupa, Volume 04 Nomor 03.

Muwaffaq, Abid \& Hadi, Musthofa. 2018. Pengaruh Desain Interior dan Desain Eksterior terhadap Keputusan Pembelian pada Tasya Fashion Malang. J A B Jurnal Aplikasi Bisnis Volume:4 Nomor:1, Juni 2018.

Novita Sari. 2018. Analisis Brand Image The Coffee Cafe Bandar Lampung. STIE Gentiaras

Purwana ES, Dedi, Rahmi, Aditya, S. (2017). Pemanfaatan Digital Marketing bagi Usaha Mikro, Kecil, dan Menengah (UMKM). Jurnal Pemberdayaan Masyarakat Madani (JPMM). 
Roosinda dan Salshabila - Rebranding Koperasi INTAKO Melalui Program Redecor ...

Pramatatya, V., Najib, M., dan Nurrochmat, D. R. (2015). Pengaruh Atmosfer Kedai Kopi terhadap Emosi dan Keputusan Pembelian Ulang. Jurnal Manajemen dan Agribisnis, Vol. 12, No. 2, 126-136.

Ramadhan, Fadli Harisa. 2017. Pemanfaatan Media Sosial Instagram Akun @Mr.Creampuff Sebagai Promosi dalam Meningkatkan Penjualan. Jurnal JOM FISIP Vol. 4 No. 2 - Oktober 2017.

Rifianita, Renata Dini \& R. Sugeng Basoeki. 2019. Pengaruh Store Layout dan Keragaman Produk Terhadap Keputusan Pembelian (Studi Kasus Pada Seamart Swalayan Malang). J A B Jurnal Aplikasi Bisnis, Volume:5 Nomor:3.

Hartono, Rudi., Arifin, Rois \& Hufron, Moh. 2020. Pengaruh Strategi Promosi Sosial Media (Instagram) dan Word of Mouth Terhadap Keputusan Pembelian Kuliner Mbok Taya. e-Jurnal Riset Manajemen PRODI MANAJEMEN Fakultas Ekonomi dan Bisnis Unisma.

Setiawati, A. A Diah DanSukawati, Tjok. Gde Raka. 2017. Pengaruh Merchandise dan Atmosfer Gerai terhadap Nilai Hedonik dan Perilaku Pembelian Impulsif di Lippo Mall Kuta. E-Jurnal Manajemen UNUD, 6(9), pp.5205-523.

Suhartanto, Dwi, Tjetjep Djatnika, Ruhadi \& Ni Nyoman Triyuni. 2017. Ritel. Bandung: Alfabeta.

Sutikno, M. Sobri. 2007. Strategi Belajar Mengajar. Bandung: Refika Aditama.

Utami, Christina Widya. 2012. Manajemen Ritel. Strategi dan Implementasi Operasional Bisnis Ritel Modern di Indonesia. Jakarta: Salemba Empat.

Vita Dhameria, S. (2014). Analisis Pengaruh Keunikan Desain Kemasan Produk, Kondusitivitas Store Environment, Kualitas Display Produk terhadap Keputusan Pembelian Impulsif (Studi pada Pasaraya Sri Ratu Pemuda Semarang). Jurnal Sains Pemasaran Indonesia, XIII(1), 1-44.

Wardhana, H. W. K., \& Rochmaniah, A. (2008). Pengaruh Display Product terhadap Keputusan Pembelian Konsumen PT. Ace Hardware Sidoarjo. Jurnal Kanal, 1(1), 1-101.

We Are Social. 2018. 2018 Digital Yearbook: Headline Internet, Social Media, and Mobile Use Data for Every Country in The World. We Are Social.

Wibowo, Bambang Setia \& Haryokusumo, Diaz. 2020. Peluang Revolusi Industri 4.0 Bidang Pemasaran: Pemanfaatan Aplikasi Ecommerce, Sosial Media Instagram dan Digital Marketing terhadap keputusan Instant Online Buying Konsumen Generasi Millenial. Jurnal Ekonomi Dan Manajemen Vol 3 No 2. 